\title{
Silêncio e interdito em questões de interpretação de texto de um livro didático de Língua Portuguesa
}

\author{
Silence and probibition on issues of interpretation of the text in a Portuguese's \\ book language teaching \\ Palmira Heine* \\ Universidade Estadual de Feira de Santana, Feira de Santana, Bahia, Brasil \\ Flágila Marinho** \\ Universidade Estadual de Feira de Santana, Feira de Santana, Bahia, Brasil
}

\begin{abstract}
Resumo: Este trabalho objetiva discutir os modos de funcionamento do silêncio no livro didático de Língua Portuguesa da Coleção Diálogo. Com base na Análise de Discurso de linha francesa, observouse que ocorre uma interdição do acesso à polissemia, impedindo o aluno de acessar os múltiplos sentidos, levando-o apenas a copiar e transcrever partes explícitas do texto. Os resultados mostram que o processo de interpretação de texto proposto nas questões analisadas pressupõe um sujeito passivo que apenas repete sentidos explicitados no texto, sem acessar os elementos históricos e ideológicos que constituem os sentidos na língua.
\end{abstract}

Palavras chave: Texto. Interpretação. Silêncio. Livro Didático.

\begin{abstract}
This paper aims to discuss the silence and its operating modes in the Portuguese Language textbook of Dialogue Collection. Based on the French Discourse Analysis. Results showed that access to multiple meanings is forbidden and students are only allowed to copy and transcribe explicit parts of the text. The text interpretation process proposed in the analyzed questions requires a passive subject who just repeats the explicit meanings of the text.
\end{abstract}

Keywords: Text, interpretation, silence, Textbook

\section{INTRODUÇÃO}

$\mathrm{O}$ presente artigo tem como objetivo analisar a forma como o silêncio funciona no livro didático de Língua Portuguesa, Coleção Diálogo, a partir da observação das questões de interpretação de texto. Parte-se do princípio que o livro didático é um elemento ideológico constituinte do discurso pedagógico, sendo este último marcado, na maioria das vezes por um discurso autoritário que interdita a voz do aluno na construção de sentidos do texto. Assim, o aluno passa a ser um mero "repetidor de sentidos", não sendo capaz de expor seu olhar aos não ditos, aos elementos históricos e ideológicos que compõem o texto, sendo, apenas levados a repetir sentidos legitimados no discurso pedagógico, sentidos presentes nos livros didáticos e por ele disseminados através de questões de interpretação de texto.

Para a análise de dados recorre-se aos pressupostos teórico-metodológicos da Análise de Discurso de linha francesa, de vertente pecheutiana, que concebe a língua como um sistema relativamente autônomo constituído inexoravelmente por

\footnotetext{
* Professora do Departamento de Letras e Artes da Universidade Estadual de Feira de Santana, Bahia, Brasil.

** Mestra em Linguística pela Universidade Estadual de Feira de Santana. Professora da rede Municipal de Feira de Santana, Bahia, Brasil.
} 
elementos históricos e ideológicos. Dentre as categorias teóricas selecionadas, destaca-se a categoria do silêncio que será utilizada para analisar os dados. Para isso, será discutido aqui o silêncio como elemento essencialmente discursivo, gerador de sentidos.

\section{O SILÊNCIO E A CONSTIUIÇÃO DE SENTIDOS}

O silêncio é a parte que não se vê, que não se pode apontar de maneira explícita ou clara, mas que efetivamente significa nos discursos. Aliás, só há sentido porque há silêncio que permite que o discurso signifique e seja moldado a partir de inúmeros traços sócio-históricos. Assim, o silêncio significa e, no jogo dos sentidos, constitui-se como elemento importante para a compreensão do discurso. O silêncio é a condição mesma de possibilidade dos sentidos. É ele que possibilita que o sujeito, se apropriando da linguagem, faça o uso da mesma na geração de sentidos. A linguagem surge quando o silêncio é rompido. O rompimento do silêncio é, portanto, o primeiro passo para os que sentidos se instaurem no jogo polissêmico do discurso. Em outras palavras, só se diz algo porque há um silêncio anterior que permite que os sentidos sejam instaurados. Quando se diz, se silencia e o silêncio indica posições do sujeito no discurso. Segundo Orlandi (2007), a palavra aparece, portanto, como movimento ao redor do silêncio, que é fundante. O sujeito fala a partir de um todo de sentido e quando ele diz algo, rompe o silêncio para acessar partes do sentido que se encontra na dimensão sócio-histórica anterior à palavra.

Há várias formas de funcionamento do silêncio. Sabe-se, a partir dos estudos discursivos, que o silêncio funciona de vários modos e que o funcionamento do mesmo regula a constituição dos sentidos, por vezes restringindo-os e controlandoos, por outras, ampliando-os e colocando-os dentro da dimensão da polissemia. A seguir explicitaremos os modos de funcionamento do silêncio com base em Orlandi (2007).

Inicialmente há o silêncio fundador. Antes do discurso veio o silêncio. $\mathrm{O}$ silêncio nessa perspectiva é fundador da atividade discursiva. Antes da linguagem, o silêncio, antes do discurso, o silêncio. Assim, o silêncio é o real da significação. A significação, aliás, só existe, porque há silêncio. Segundo a autora, o silêncio fundador é necessário, indispensável para que os sentidos se construam. Sem o silêncio fundador não há sentidos. Para Orlandi (2007, p. 45), "[...] O silêncio não é um acidente que intervém ocasionalmente: ele é necessário à significação". Isso implica pensar que sem o silêncio aconteceria o non sense, ou seja, o não sentido por meio do que ela denomina de o "muito cheio" da linguagem. Ou seja, sem o silêncio, todos os sentidos estariam, ao mesmo tempo, sendo ditos, instaurando o impossível na comunicação.

Além do silêncio fundador, existe o que a autora chama de políticas de silenciamento, que é o pôr em silêncio. No caso das políticas de silenciamento, algo é silenciado, é colocado em silêncio. Esse colocar em silêncio pode ser algo feito de forma a calar o sujeito (o não poder dizer, a interdição, a censura) ou de forma a se dizer algo para não se dizer outra coisa. As políticas de silenciamento representam, portanto, um movimento dos sujeitos que, ao se inserirem na atividade discursiva, 
são levados a silenciarem algo, diferentemente do silêncio fundador que existe antes mesmo da linguagem, porque para se dizer é preciso que antes haja silêncio.

As políticas de silenciamento, por sua vez, se dividem em: silêncio constitutivo e silêncio local. O silêncio constitutivo indica que quando se diz algo, é preciso silenciar outra coisa, ainda que tal movimento não seja consciente. Para dizer, é preciso não dizer.

Consoante Orlandi (2007) o silêncio constitutivo:

\begin{abstract}
Representa a política do silêncio como um efeito de discurso que instala o antiimplícito: se diz " $\mathrm{x}$ " para não (deixar) dizer " $y$ ", este sendo o sentido a se descartar do dito. É o não-dito necessariamente excluído. Por ai se apagam os sentidos que se quer evitar, sentidos que poderiam instalar o trabalho significativo de uma "outra" formação discursiva, uma "outra" região de sentidos. O silêncio trabalha assim os limites das formações discursivas, determinando consequentemente os limites do dizer. (ORLANDI, 2007, p. 73-74).
\end{abstract}

O silêncio constitutivo relaciona-se, então, com a posição que o sujeito ocupa na atividade discursiva. Ele diz algo para não dizer outra coisa. A partir da posição sujeito, ele diz coisas que podem ser ditas e silencia outras que não podem ser ditas na conjuntura comunicativa em que se insere.

O outro elemento constitutivo das políticas de silenciamento é o silêncio local. Esse é o silêncio da censura. É o não poder dizer por que há um controle sobre o que se diz, interditando sentidos. No silêncio local, o sujeito é impedido de dizer o que poderia ser dito. A ele é imposto o controle dos sentidos, silenciandoos. O silêncio local é proveniente da censura e da interdição. A censura produz materialidades. No período da ditadura militar no Brasil, o que não se podia dizer aparecia em forma de página em branco, ou em forma de uma receita de algum alimento, por exemplo. O aparecimento dessas materialidades indicava que não se pôde dizer algo, indicava a interdição de sentidos. O que não se pode dizer é interditado, o sujeito impedido de acessar determinados sentidos.

Nesse artigo, pretende-se mostrar como o silêncio funciona na construção de sentidos no livro didático, a partir de questões de interpretação de texto. Parte-se da ideia inicial de que o sujeito aluno é interditado, impedido de produzir sentidos que não estejam explícitos no livro didático, havendo, portanto, o funcionamento do silêncio local. Ao aluno, não será possível acessar a polissemia, os múltiplos sentidos que constituem os textos analisados, mas ele será levado apenas a observar os textos na sua superfície explícita e concreta. A interdição de sentidos é um modo de controle dos sujeitos, é uma forma de controle da polissemia, para que a língua termine sendo controlável. É, portanto, algo passível de repetição, de extração de sentidos prontos. E a escola, muitas vezes, coloca-se na esteira do controle dos sentidos. 


\section{O LIVRO DIDÁTICO COMO UM ELEMENTO IDEOLÓGICO DENTRO DO DISCURSO PEDAGÓGICO}

Segundo Althusser (1985) a ideologia é constitutiva do sujeito e este não pode dela escapar. Não há sujeito que esteja fora da ideologia, sendo esta entendida como uma prática que se materializa de diversos modos. Althusser indica que a ideologia é a representação da relação imaginária dos indivíduos com suas condições reais de existência. É nessa relação imaginária que os sujeitos se constituem. Aliás, segundo o autor, o homem é um "animal ideológico", e a ideologia interpela os indivíduos em sujeitos. Para Althusser (1985), não se pode compreender a ideologia como um simples conjunto abstrato de ideais, ao contrário, toda ideologia tem uma existência material na medida em que os sujeitos moldam suas práticas sociais a partir das ideologias que lhes interpela. A ideologia se materializa principalmente a partir dos Aparelhos Ideológicos do Estado, instituições que têm como função reproduzir e difundir as idéias dominantes. Dentre os Aparelhos Ideológicos do Estado destacase o Aparelho Escolar, sendo este um dos primeiros e primordiais meios pelos quais a ideologia é difundida. A escola, muitas vezes, funciona como difusora das idéias da classe dominante formando sujeitos diferenciados: uns para serem donos de suas próprias empresas, outros para serem empregados delas.

O discurso pedagógico, por sua vez, é classificado por Orlandi (1987) como um discurso autoritário. A autora identifica algumas características do discurso autoritário, dentre elas destacam-se: a falta de reversibilidade entre os interlocutores, e o controle da polissemia. Assim, a autora argumenta que a escola, ao centrar suas práticas no ensino tradicional, impede a reversibilidade do discurso, impedindo que a voz do sujeito leitor seja valorizada. Ao mesmo tempo, o aparelho escolar controla a polissemia, fazendo com que somente sentidos legitimados e aceitos possam ser produzidos.

Tfouni e Paula, ao falarem sobre o discurso pedagógico afirmam que:

O Discurso Pedagógico Escolar (DPE) tradicional ainda é o discurso dominante no espaço da escola pública brasileira. É esse o discurso que sustenta a maioria das práticas escolares desenvolvidas nesse espaço institucional, fato que, se considerarmos a forma (autoritária) de funcionamento do DPE, pode ser muito significativo para pensarmos as problemáticas do campo da Educação.

Assim, os autores supracitados chamam a atenção para o fato de que, apesar da existência de ampla literatura crítica às práticas pedagógicas tradicionais, estas ainda continuam sendo dominantes no ambiente escolar. O discurso pedagógico vê a língua como um sistema essencialmente formal, em que mais importa ensinar a gramática normativa do que gerar sujeitos pensantes, capazes de lerem os implícitos dos textos. A língua se confunde com as regras gramaticais e estas últimas são as mais valorizadas no discurso pedagógico tradicional.

Ao observar a língua como um sistema completamente formal, descarta-se o fato de que ela é desde sempre afetada pela história e pela ideologia. Descarta-se o fato de que os sentidos não são fixos mas variam em relação às posições ocupadas 
pelos sujeitos, trazendo à tona elementos sócio-históricos e ideológicos. Ao descartar tais elementos, o discurso pedagógico tradicional impede os alunos leitores de produzirem sentidos que não estejam explicitados no sistema formal da língua, impedindo que os mesmos acessem as zonas do implícito e do não dito. Os sujeitos alunos leitores, desse modo, tornam-se sujeitos repetidores de sentidos e não sujeitos capazes de lerem os não ditos e os relacionarem com elementos da história.

Partindo dessas observações, interessa observar e analisar como a escola age, a partir do livro didático, para silenciar o aluno, impedindo-o de acessar a polissemia. E é isso que vai ser debatido no item a seguir.

\section{O LIVRO DIDÁTICO E O FUNCIONAMENTO DO SILÊNCIO NA INTERDIÇÃO DOS SUJEITOS}

Pretende-se enfatizar nesse ponto, a partir da análise de exercícios de interpretação de texto presentes no livro didático da Coleção Diálogo, a constituição do sentido a partir do funcionamento do silêncio nas questões que prezam por um trabalho com a leitura parafrástica, ou seja, com a leitura que envolve apenas um processo pouco reflexivo envolvendo exclusivamente a repetição de sentidos e a extração de partes de textos.

Em algumas questões que envolvem a construção do sentido do texto, podemos concluir, por meio das análises, que o silêncio funciona como interdição à polissemia, na medida em que cobra um sentido institucionalizado, tido como verdadeiro e legitimado, silenciando outras possibilidades de leituras, de sentidos. Vejamos, então, as análises:

Figura 1 - Exemplo 01
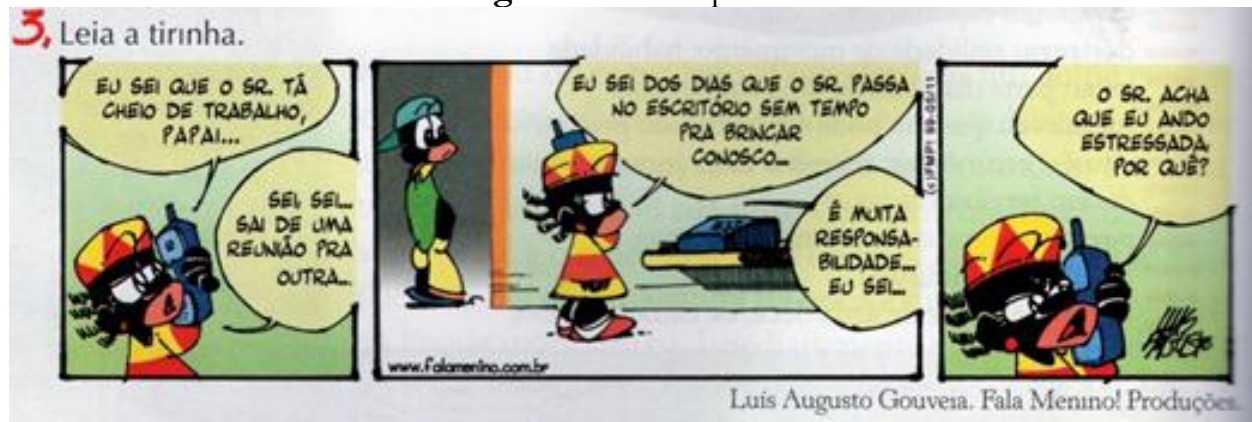

a) Transcreva da resposta de Lucas a um dos rapazes da comunidade uma frase que transmite, com outras palavras, a ideia da turınha. "A gente vive uma vida muito cheia de co pra fazer Lá a gente tem obrigaçóes que aqui vocếs năo têm. / Temos cobranças da sociedade, da familia !

Fonte: Livro didático de Língua Portuguesa, Coleção Diálogo, $6^{\circ}$ ano, p. 170.

A questão em destaque faz parte do texto 2 do $4^{\circ}$ módulo do $6^{\circ}$ ano do livro Língua Portuguesa Coleção Diálogo e tem como título "Lucas Pescador". Antes dessa tirinha, havia sido colocado um outro texto intitulado Lucas Pescador. Nele, o autor descreve a experiência do jovem, Lucas de 14 anos, que faz uma viagem a uma aldeia indígena, na companhia de Daniel Munduruku (narrador da história) e 
personagem indígena brasileiro. No transcorrer dos acontecimentos, de uma forma geral, a discussão gira em torno das diferenças entre a cultura branca e a cultura indígena, como, por exemplo, a maneira de conseguir o sustento na cultura indígena, como se dá o aprendizado, a maneira de lidar com o tempo, o sofrimento, o respeito à natureza, elementos que diferenciam tal cultura da cultura branca. Lucas mostra-se curioso e aprende muito sobre o modo de vida dessa comunidade, seus costumes, crenças e, sobretudo, a relação que esta tem com a natureza. A tirinha, então, colocada no exemplo 1, anteriormente trazido, tem o objetivo de trazer o debate sobre a questão do tempo, em um diálogo com o texto Lucas Pescador, para que o leitor possa perceber a diferença entre o modo como o tempo é concebido para os grupos indígenas, que foram tema do texto anterior, e o modo como a sociedade capitalista concebe o tempo. Assim, o exemplo 1 traz uma tirinha cujo tema é o tempo. Na questão, vê-se que a formulação pede que o sujeito leitor leia a tirinha. Nesta há o seguinte diálogo protagonizado entre pai e filha, mas somente a voz da filha é colocada, como se pode ver: "Eu sei que o Sr. tá cheio de trabalho, papai..."; "Sei sei... sai de uma reunião pra outra...”. O diálogo continua e dessa vez aparece outra criança, supostamente outro filho, já que ela usa o "conosco", demonstrando que não é filha única. Esta outra criança passa e observa a conversa, "Eu sei dos dias que o Sr. passa no escritório sem tempo pra brincar conosco..."; "É muita responsabilidade eu sei...”; e, então, a filha finaliza "O Sr. acha que eu ando estressada por quê?".

Seria, portanto, uma boa oportunidade de o livro problematizar essa representação da questão do tempo para a sociedade capitalista, os sentidos diversos da falta de tempo dos pais para com os filhos, da vida corrida cheia de afazeres e com pouco tempo para se dedicar à família, dentre outras coisas, retomando os já ditos, mostrando como essas ideias interpelam os sujeitos e os constituem. Seria um momento oportuno para se debater o modo como os cidadãos das sociedades ocidentais naturalizam a falta de tempo não havendo reflexão sobre suas consequências, estabelecendo aí uma contraposição ao tempo nas sociedades indígenas com o qual se propõe uma comparação. Entretanto, o que ocorre é, apenas um pedido de transcrição: "transcreva da resposta de Lucas a um dos rapazes uma frase que transmita, com outras palavras, a ideia da tirinha". Com essa assertiva, o sujeito leitor terá apenas que procurar no texto em que ocorre a conversa dos sois personagens, o momento que Lucas responde ao índio sobre a falta de tempo. Assim há uma predominância com o trabalho parafrástico (ou seja, com o trabalho que preza pela repetição e cópia de sentidos) em detrimento da polissemia (o acesso a outros sentidos). Chama a atenção o comando em "outras palavras", colocado na questão, que, apesar de indicar uma pretensa liberdade do sujeito dizer com outras palavras, direciona para o mesmo sentido.

O sujeito terá que produzir o mesmo sentido produzido pelo texto, porém com diferentes palavras, não havendo espaço para outro sentido, mas apenas para aquele legitimado pela questão. Há uma busca por um sentido, literal, impar, e imprescindível, para que se possa legitimar a resposta. Agora, vamos observar a parte do texto que contêm essa ideia da diferença entre a noção de tempo para os indígenas e não indígenas a partir da fala do personagem Lucas, explicitando como o LD prima por uma abordagem parafrástica, impedindo o acesso a outros sentidos. 
Figura 2 - Trecho 1

lá é muito diferente. A gente vive uma vida muito cheia de coisas pra fazer. Lá a gente tem obrigações que aqui vocês não têm. Temos cobranças da sociedade, da família da escola, dos nossos amigos... Temos que aprender mi

Fonte: Livro didático de Língua Portuguesa, Coleção Diálogo $6^{\circ}$ ano, p. 166.

Essa passagem do texto mostra Lucas (o menino que vai passar uns dias em uma aldeia) em diálogo com alguns rapazes da aldeia (índios). Lucas fala a um deles sobre como é a vida das pessoas na cidade e atrela a noção da falta de tempo a ter "muitas coisas pra fazer", "ter obrigações", "cobranças" enunciados que promovem um efeito de sentido que dialoga com a ideia da tirinha da questão colocada no exemplo 01. Nesse sentido, tal passagem se configura como a resposta solicitada pela atividade.

O sujeito leitor não terá muitas dificuldades de encontrar essa parte do texto, pois o próprio comando da questão facilita por meio da indicativa "momento em que Lucas responde". Assim, basta que o sujeito leitor se dirija ao texto e procure por esse momento para localizar o sentido pretendido pela questão. Isso pode ser confirmado com a expressão "transmite (...) a ideia da tirinha" indicando a existência de um sentido pronto que deve ser transmitido e captado pelo sujeito leitor, o que nos leva a perceber a existência de uma ideologia que regula o sentido de língua, neste caso, a ideologia regula o sentido de língua como transparente, através da qual se extraem sentidos prontos. Por sua vez, essa questão requer um trabalho com a inteligibilidade (decodificação), pois ao propor uma transcrição pura e simples de um determinado trecho, privilegia o trabalho da decodificação, o sentido unilateral, e uma concepção de texto como unidade fechada em si mesma, sem relação com os aspectos históricos, sociais e ideológicos. No caso da questão do exemplo anterior, observa-se o funcionamento do silêncio local. O sujeito é impedido de acessar o interdiscurso e precisa reproduzir partes do texto para responder à questão. Desse modo, há o funcionamento do discurso pedagógico autoritário que ainda que explicitamente não se apresente como um discurso que restringe e controla os movimentos de interpretação do sujeito, o faz de modo a impedi-lo de gerar outros sentidos que coloquem o dito em relação ao não dito.

Orlandi (2012) em suas reflexões tem defendido o trabalho com a leitura nos espaço escolar considerando a polissemia dos sentidos, sem descartar o processo parafrástico, mas afirmando que é preciso ir além, vendo o texto como um objeto linguístico-histórico e por isso suscetível de leituras diferentes, as chamadas múltiplas leituras. Entretanto, atividades como esta ainda têm tido cada vez mais espaço no livro didático (LD) o que demonstra primazia pela leitura parafrástica em detrimento da polissêmica.

Ratificando a afirmação anterior, segue mais um exemplo de questão que adota uma postura de leitura parafrástica cujo foco é a reprodução de um dado trecho do texto, dessa vez a questão é do texto 1 , do $3^{\circ}$ módulo do $9^{\circ}$ ano.

Novamente, por se tratar de um texto ainda não abordado nesse artigo, fazse necessária uma contextualização com um sucinto resumo. Pois bem, o texto 1 
do $3^{\circ}$ módulo do livro do $9^{\circ}$ ano tem como título "Histórias de mãe e filho", do escritor Moacyr Scliar (2006). O texto é um conto e quem narra é o filho de Raquel. Assim, o narrador conta a história de Raquel e sua família que saem da Rússia fugindo da pobreza e das perseguições causadas pela guerra.

O lugar escolhido para o refúgio, por meio de uma publicidade de colonização, foi o Brasil. A família de Raquel segue para o Brasil em busca de melhores condições de vida. Raquel era uma moça simples que amava ler livros e na viagem clandestina ao Brasil conhece Davi que também fugia da Rússia para o Brasil como tantas outras famílias, e também gostava de ler.

O amor aos livros fez os dois criarem um sentimento de amizade tão grande que posteriormente descobrem-se apaixonados. Algumas famílias de imigrantes russos (como a de Davi) passaram por dificuldades de adaptações, principalmente no trabalho com a lavoura. E decidem arriscar a sorte na cidade grande (São Paulo). Esse fato separa Raquel de Davi que mantém contato por cartas. Posteriormente a família de Raquel também deixa a lavoura e resolve ir morar em São Paulo a convite da família de Davi. Raquel e Davi se casam e continuam com seu amor pelos livros, pela leitura, cinema, teatro, pelas artes em geral. Grávida, Raquel lia constantemente, agora, para seu filho no ventre. Raquel morre no parto e Davi continua com a prática de leituras para o filho, mantendo vivo o desejo da esposa, que sonhava vêlo um grande leitor e se possível um grande escritor.

O desejo foi realizado, pois o narrador da história (filho de Raquel) é também o escritor do conto. Por meio desse conto Moacyr Scliar mostra-se apaixonado pela história de seus pais e a maneira como eles influenciaram na sua paixão pela leitura e pela escrita, hoje um grande escritor.

Segue uma das questões que propõe analisar o texto:

Figura 3 - Exemplo 02

2. Segundo o narrador, a escolha do Brasil como um lugar para emigrar surgiu devido a um
folheto distribuído por uma companhia de colonização. Nele, um desenho chamava a
atenção.
a) Que aspectos culturais e geográficos foram destacados no desenho do folheto que
assinalam as diferenças entre o Brasil e o sul da Rússia?
O sol brilhando em um céu azul, campo com árvores frutifferas, uma menina lendo um livro.

Fonte: Livro didático de Língua Portuguesa, Coleção Diálogo 9ª ano, p. 108.

Podemos verificar mais um exemplo de leitura parafrástica. A questão trabalha a imagem feita do Brasil por meio de um folheto numa campanha de colonização. Esse aspecto poderia ser explorado pela questão, enfatizando as condições de produção desse discurso, procurando desafiar o sujeito-leitor com questionamentos do tipo: como o Brasil é representado nessa imagem? Porque uma campanha de colonização? e o porquê de tais elementos aparecerem nessa imagem e não outros? No entanto, a questão decide adotar, mais uma vez, o processo de decodificação de parte do texto, impedindo o aluno leitor de acessar as regiões de sentido da polissemia. Isso ocorre, pois, ao perguntar "Que aspectos culturais e 
geográficos" "foram destacados no desenho do folheto" basta voltar à leitura e encontrar a parte em que há a descrição do folheto apresentado na Rússia.

Segue, deste modo, o trecho em que o sujeito leitor pode encontrar a resposta da atividade:

Figura 3 - Trecho 2

Na capa do folheto havia um desenho, colorido, mostrando um agricultor trabalhando no campo, sob um céu muito azul. Ao fundo, árvores frutíferas - uma laranjeira carregada de laranjas - e animais: vacas, cabritos, cavalos... Na janela da casa, năo muito grande, mas muito bonita, várias crianças, todas sorrindo felizes, e uma delas lendo um livro. Um letreiro dizia: "Brasil: aqui está o futuro".

Brasil? É depois de Odessa?

Brasil? - perguntou minha avó. - Onde fica o

Fonte: Livro didático de Língua Portuguesa, Coleção Diálogo 9ª ano, p. 102.

Pelo trecho acima, podemos concluir que este é o espaço circunscrito pela questão. Dessa forma, o sujeito leitor no decorrer das questões precisa tão somente destacar os aspectos geográficos (céu muito azul, árvores frutíferas) e o aspecto cultural, nesse caso representado pelo livro (uma menina lendo um livro).

A marca linguística "segundo" (preposição), no trecho da pergunta "Segundo o narrador", a princípio, traz o efeito de sentido de que o sujeito leitor vai se basear no texto, para a partir dele, observar a ideia do narrador, o que culminaria para um trabalho de interpretabilidade restrito ao que disse o narrador, pois o foco para geração de sentido estaria na imagem do sujeito autor. Todavia, o que ocorre é um trabalho de inteligibilidade, uma vez que o comando é de localização e transcrição, apenas. O enunciado "foram destacados" também contribui para que possamos apreender como a questão formulada opta em trabalhar a inteligibilidade, pois esse enunciado ratifica a explicitude dos sentidos. Em todo o caso, tanto a inteligibilidade quanto a interpretabilidade são processos que desencadeiam o trabalho com a reprodução de sentidos, com pouco espaço para a irrupção do sentido outro. Afinal, estas se caracterizam como o reconhecimento que pode ser desenvolvido tanto pela reprodução como pela reformulação do sentido ofertado pelo sujeito autor (ORLANDI, 1996). Questões assim ratificam a posição ideológica do $\mathrm{LD}$, a língua dotada de transparência se constituindo como instrumento de comunicação em que os sentidos são transmitidos de um interlocutor ao outro sem interferências, não há equívoco e o conteúdo deve ser codificado da forma como foi "planejado". Esta ideia de língua é comum ao discurso pedagógico tradicional e revela mais uma vez o funcionamento da interdição dos sentidos. Há aí o funcionamento do silêncio local que interdita o sujeito, impedindo-o de acessar os múltiplos sentidos do texto. A esse sujeito cabe apenas a transcrição e cópia de trechos explícitos, sem um trabalho reflexivo que possa embasar a interpretação.

Questões como essas indicam a ideia que se faz do sujeito: um mero repetidor de sentidos, incapaz de acessar elementos da memória e da história para se construir como leitor. O silêncio local age, desse modo, limitando o movimento do sujeito. 
Ele precisa ficar preso ao que diz o texto, ao que enuncia o autor do mesmo, ao que diz o narrador, não podendo acessar os diversos sentidos presentes no interdiscurso para elaborar sua resposta.

Desse modo, é possível notar quais as noções de língua, sujeito e texto que embasam os manuais didáticos, sendo a língua concebida como sistema formal e o sujeito como passivo, associando tais noções ao discurso autoritário que faz com que os sujeitos precisem dar a resposta esperada às questões propostas, sem espaço para a reflexão ou discordância ou para a irrupção de outros sentidos que não estejam marcadamente explícitos no texto. Não há nas questões uma proposta de leitura reflexiva que faça o sujeito pensar sobre o que foi o processo de imigração, acessando elementos da história para construir sentidos.

\section{CONSIDERAÇÕES FINAIS}

A partir do que foi abordado através da análise dos exemplos aqui apresentados, foi possível observar o modo de funcionamento do silêncio no processo de interpretação de texto. O silêncio molda os movimentos do sujeito, interditando os sentidos múltiplos. Ao sujeito cabe a passividade, a transcrição e cópia de partes explícitas e facilmente localizáveis nos textos.

O silêncio, nesse caso, age impedindo que diversos sentidos venham à tona, controlando os sujeitos, controlando os sentidos. Na esteira do autoritarismo do discurso pedagógico tradicional, encontra-se o livro didático, que funciona como um veículo difusor da ideologia que considera a língua como autônoma e transparente, dotada de um sentido único que deve ser reproduzido pelos leitores.

Esse trabalho com o texto e com a interpretação tem gerado sujeitos com pouca competência leitora, incapazes de ler os implícitos e de fazerem relações entre o que está explicitamente colocado no texto e os não ditos que compõem o sentido do mesmo.

\section{REFERÊNCIAS}

ALTHUSSER, Louis. Aparelhos ideológicos de estado: nota sobre os aparelhos ideológicos de Estado. 3 ed. Rio de Janeiro: Graal, 1985.

BELTRÃO, Eliana Lúcia S.; GORDILHO, Tereza Cristina S. Diálogo: língua portuguesa, $6^{\circ}$ ano. Ed. renovada. São Paulo: FTD, 2009.

; GORDILHO, Tereza Cristina S. Diálogo: língua portuguesa, $9^{\circ}$ ano. Ed. renovada. São Paulo: FTD, 2009.

BRANDÃO, Helena H. Nagamine. Introdução à análise do discurso. 3. ed. rev., Campinas, SP: Editora Unicamp, 2012. 
ORLANDI. A linguagem e o seu funcionamento: as formas do discurso. 4. ed, $3^{\text {a }}$ reimpressão. Campinas: Pontes, 1996.

As formas do silêncio: no movimento dos sentidos. 6. ed. Campinas, SP: Editora da Unicamp, 2007.

Discurso e leitura. 9. ed. São Paulo: Cortez, 2012.

TFOUNI, Leda; PAULA, Fernando Silva. Regularidade e acontecimento no funcionamento do discurso pedagógico escolar. Signum, Londrina, n. 16, p.193-213, 2013. 